\title{
Efficient Single Axis Sun Tracker Design for Photovoltaic System Applications
}

\author{
Hussain S. Akbar ${ }^{1}$, Muayyad N. Fathallah ${ }^{2}$, Ozlim O. Raoof ${ }^{1}$ \\ ${ }^{I}$ Physics Dept., College of Science, Kirkuk University, Kirkuk City, Iraq. \\ ${ }^{2}$ Electronic Dept., Kirkuk Technical College, Kirkuk City, Iraq. \\ *drhussainsalihakber@yahoo.com
}

\begin{abstract}
Solar energy is rapidly gaining importance as a source of renewable energies. Solar tracker system enables be generated more solar energy by using photovoltaic solar cells. The degree of use the solar radiation can be maximized by use of tracker system which can increase the enough efficiency. It receives the largest amount of solar radiation incident when it is perpendicular to the solar panel. In this paper a one axis solar tracker is designed and implemented to track the sun in azimuth axis by using an AVR microcontroller. The implemented system consists mainly of the ATmega328 controller, DC motor, light sensors, relay and solar panel. The results show that the designed low cost sun tracker increases the output power gain by $18-25 \%$ as compared with the fixed panel located at a latitude angel $\left(35.47^{\circ}\right)$ of the Kirkuk city, Iraq. To increase the amount of incident efficiency of solar radiation conversion from the panels of the sun tracker systems has been changed by adding rear panel (back side) which is opposite to the in front panel and it was shows that the efficiency of the output power increasing about (65\%) compared with fixed panel and when adding the reflector made of Aluminum foil as (a mirror) to the opposite panel (rear panel) the output power increased about (72\%) compared to fixed system. The overall power gains on our tracker system increased and become more efficient by adding rear side panel and reflector.
\end{abstract}

Keywords - One axis tracker, Solar panel, LDR, Microcontroller, DC motor, Relay.

\section{Introduction}

Solar energy is the energy generated by harnessing the power of the solar radiation and is called photovoltaic system [1]. Photovoltaic energy is the process of converting the sunlight directly to electricity using solar cell [2]. Solar panels can be mounted as a fixed type or used as a tracker type. In the fixed type the solar panel mounted on the surface of roof or ground irrespective of sun's direction at a particular angle [3]. Solar tracker can be divided in two types' passive tracker and active tracker [4]. A solar tracker is an electronic and mechanical device that is used to the maximize absorption of solar power by adjusting the solar panel automatically to be perpendicular to the sun's radiation [5]. The single axis tracking systems realizes the movement of either azimuth or elevation for a solar power system as shown in Figure 1. The advantages of single axis solar trackers are generally a lower cost than dual-axis trackers, higher reliability than dual-axis trackers and higher lifespan than dual-axis trackers $[6,7]$.

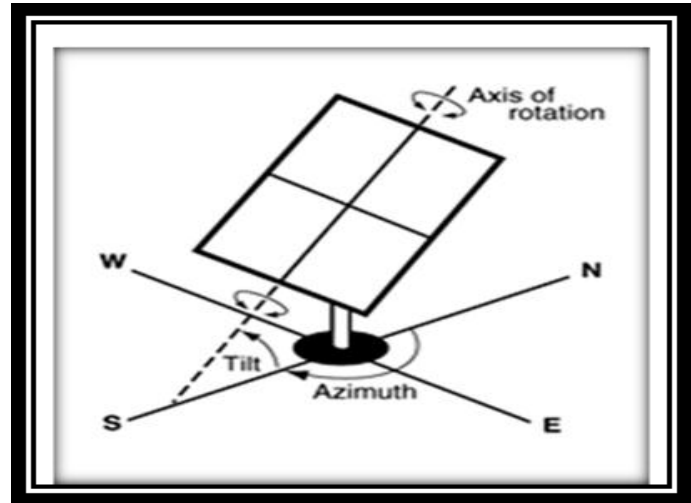

Fig.1: One axis tracker system arrangement [8].

Dual axis tracking systems realize movement both along the azimuth and elevation axis as shown in Figure 2, and are studied by many authors [9-10-11]. 


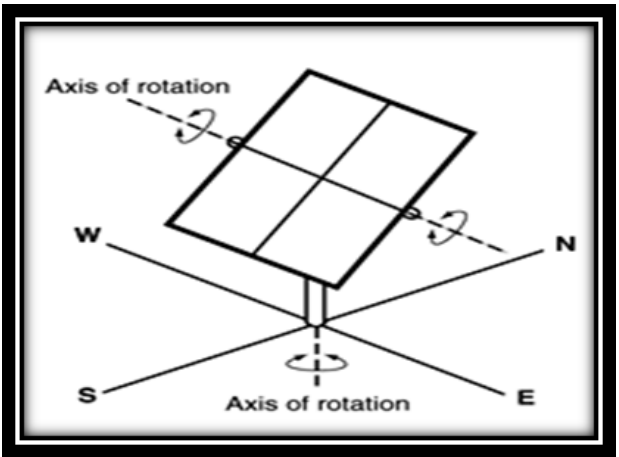

Fig. 2: Dual axis tracker system arrangement [8].

Single axis tracker system technologies have been developed by authors [12-13-14] and the implementations of the single axis tracker have done by many workers [15-16-17].

The object of this study is to design and implemented an efficient automated one axis sun tracker system and can greatly improve the output power of PV for solar energy application, which is detailed in ref. [18].

\section{Experimental Part}

The proposed tracking system tracks the sun radiation by rotating the PV panel in one axis, in which the sun rays are captured to the maximum output power by tracking system which moves at two different directions ( East-West). The proposed model for single axis tracker in our study is shown in Figure 3.

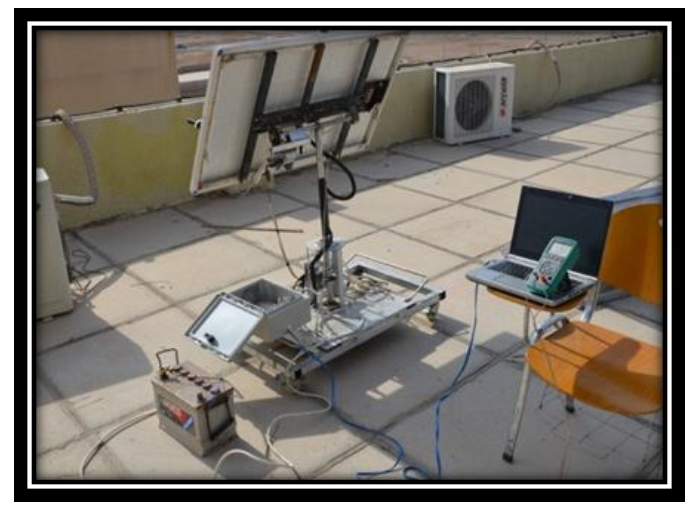

Fig. 3: The proposed model for single axis tracker.

The single axis tracking system consists of: solar panel (polycrystalline) of 87 watt which is made by Kyocera; model is KC85T-1 [19], and its area $65 \times 100 \mathrm{~cm} 2$, two photo resistors Light Dependent Resistor (LDR), Arduino Uno microcontroller ATmega328, one DC motor and two relays. DC motor and sensors are interfaced with the microcontroller which is controlling DC motor is basically performing function of sun tracking on the basis of photo sensor's input. The LDR photo sensors sense the light intensity and send signal to the microcontroller. The signal from the two sensors is always compared to detect any change in the value and then converts to digital (ADC) through Arduino Uno and decides the rotation direction of the DC motor according to the stored programing. This process explained in Figure 4 [20].

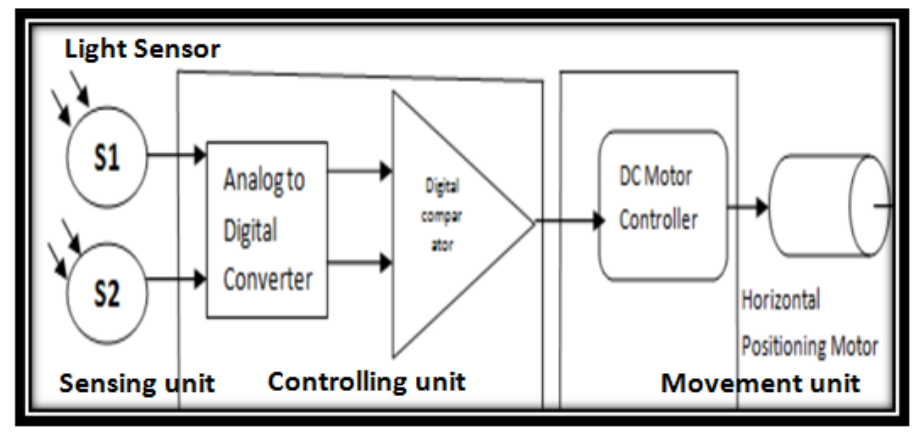

Fig. 4: Input sensing, microcontroller, DC motor units [20]. 
Figure 5 shows the block diagram of the tracking system studied in present paper. The flow chart of the control program is shown in Figure 6.

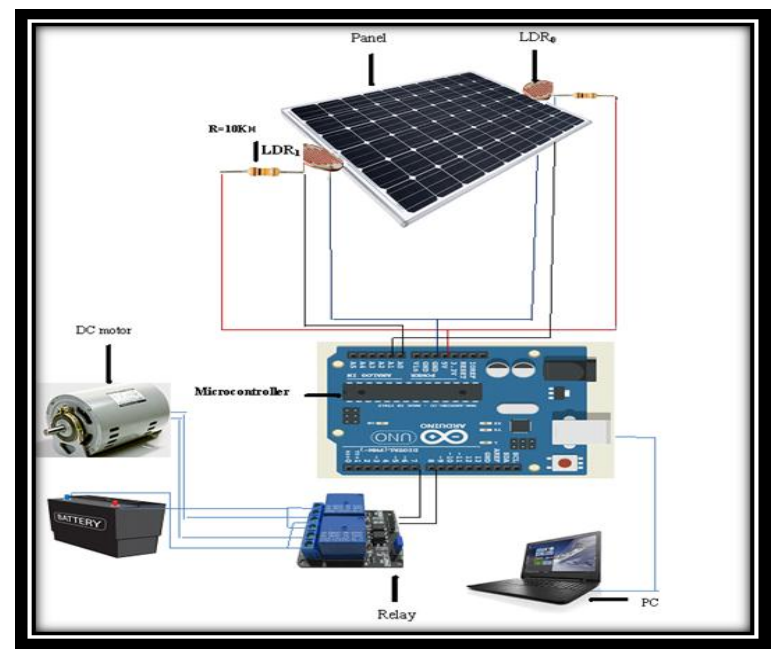

Fig. 5: Block Diagram of Tracking System.

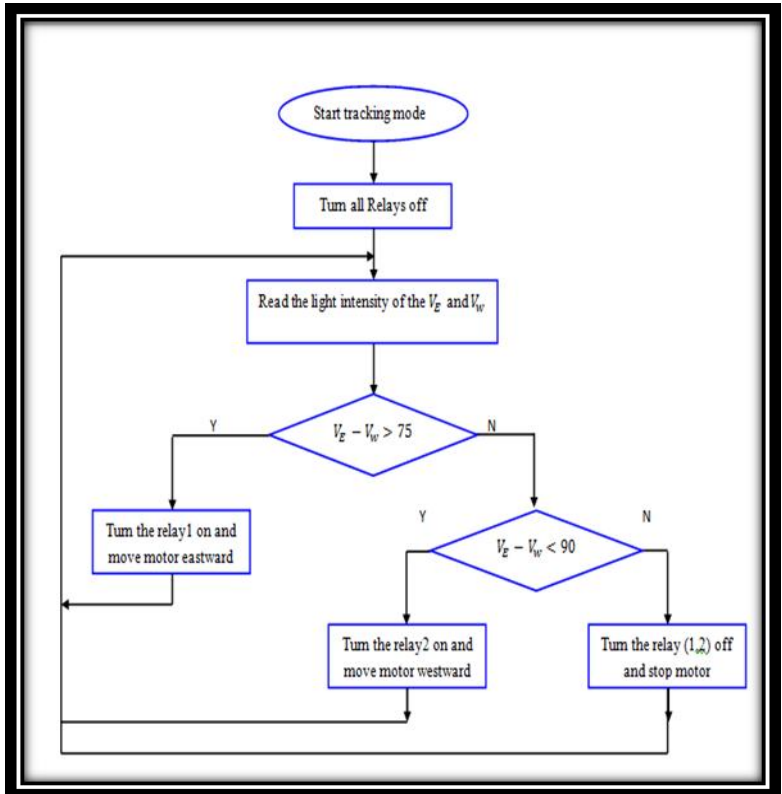

Fig. 6: Flowchart of tracking algorithm for azimuth control of system.

Algorithm starts with taking data from LDRs photo sensors. The microcontroller read this data and made a comparison between them and then decides about the movement direction of the DC motors.

The electronic circuit of the tracker system is shown in Figure 7.

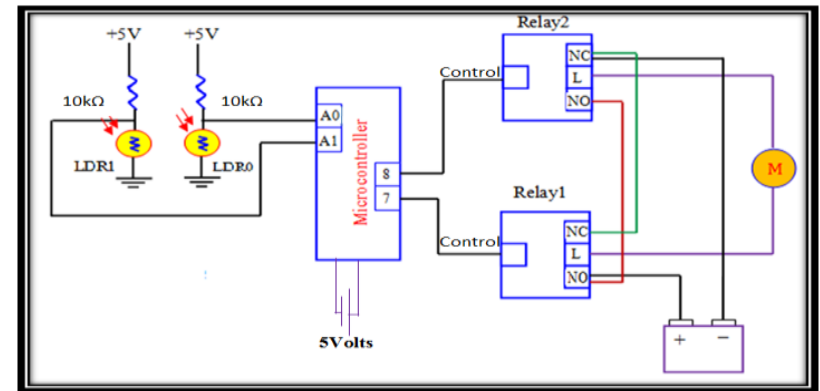

Fig. 7: Electronic circuit of tracker system. 


\section{Experimental Results}

The two PV solar panels were used, one of them was stationary at fixed angle of $35.47^{\circ}$ Kirkuk city latitude where the other was fitted on the tracker system, the setup experimental is show in Figure 8.
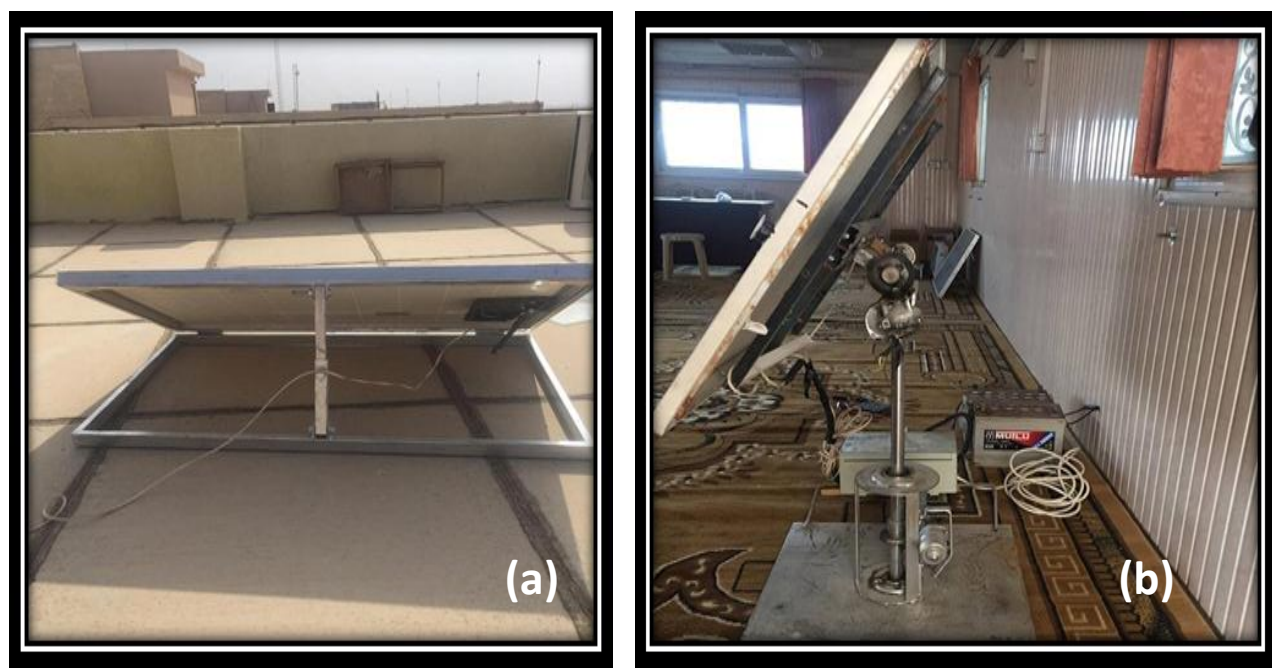

Fig. 8: Experimental setup (a: fixed system, b: tracker system).

\subsection{Output Power Measurements}

The monthly average hourly electrical output power of the two panels were calculated and plotted against the local time during hours of the day (usually 9:00 AM - 4:00 PM) for three months May, June and November were show in Figures $(9,10,11)$ respectively.

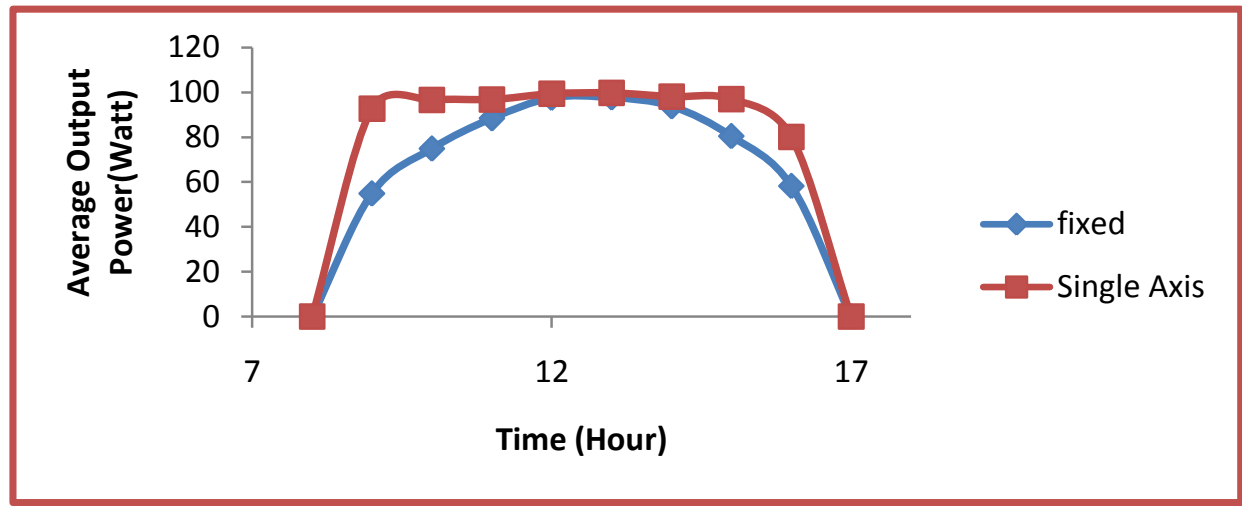

Fig. 9: Monthly average hourly variation of output power from fixed and tracking panels in month of May 2016.

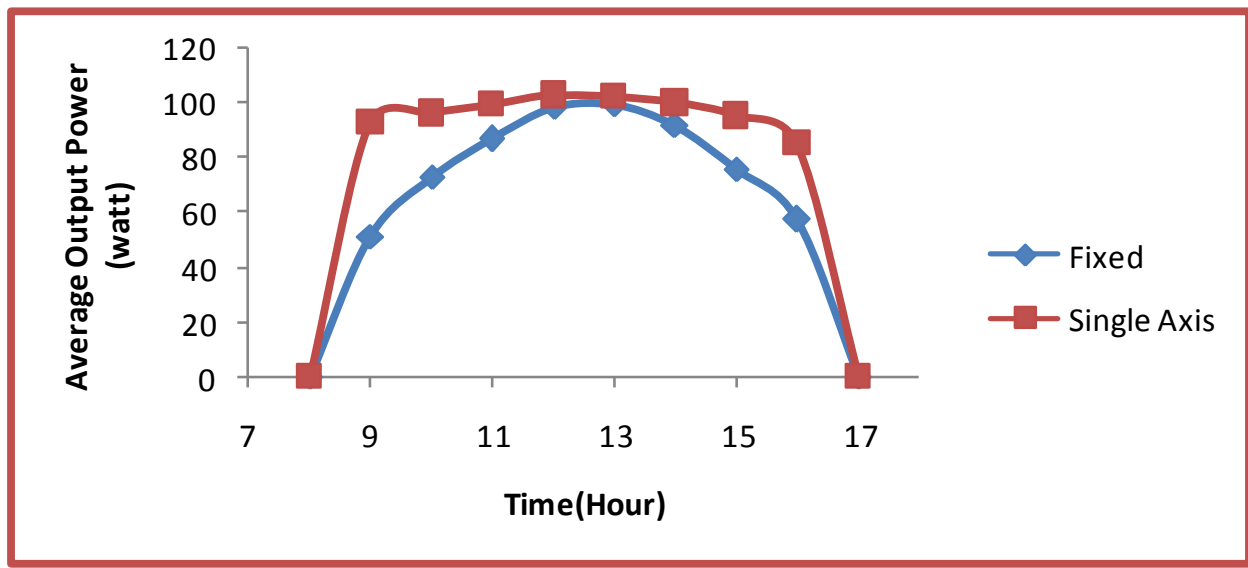

Fig. 10: Monthly average hourly variation of output power from fixed and tracking panels in month of June 2016. 


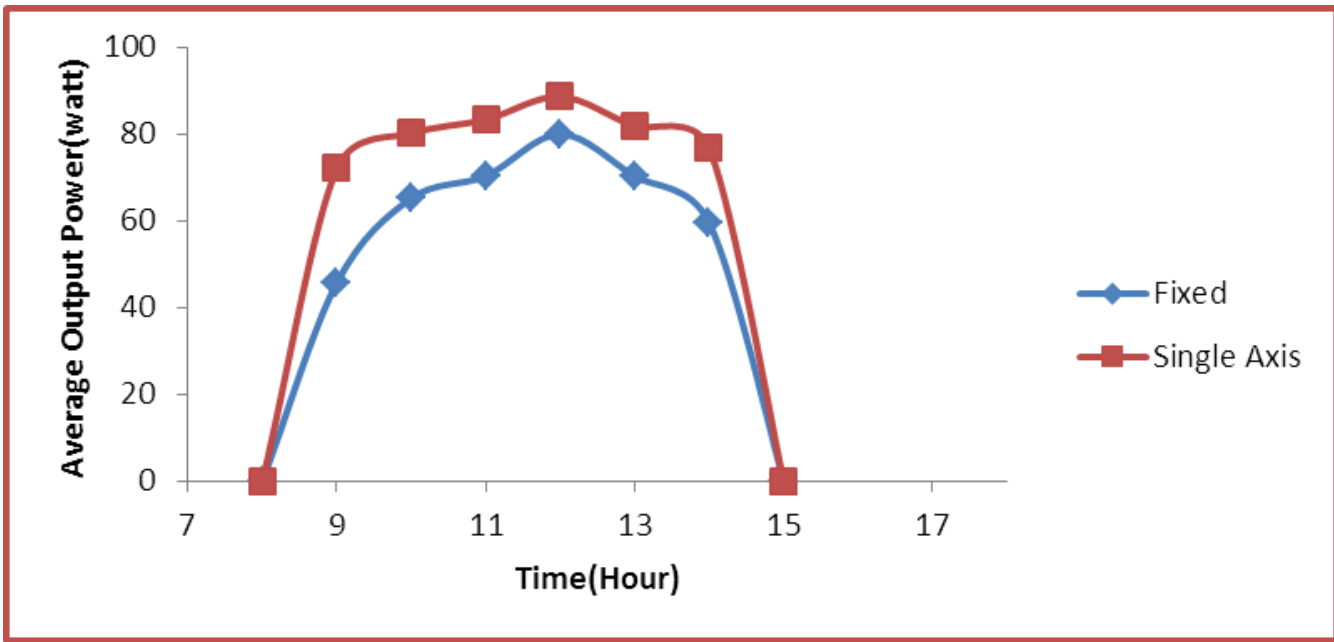

Fig. 11: Monthly average hourly variation of output power from fixed and tracking panels in month of November 2016.

It shows in May, June and November months the fixed panel variation of the output power increases gradually with time of day and reaches maximum value around 12-13 PM o'clock time and then decreases, but in single axes tracking panel the output power increases rapidly jumped up from zero to maximum value and approximately changes very little during the time except in the evening when the irradiance decreases slowly. Solar tracking system is able to receive more sunlight and consequently generate more output power compared to fixed panel because the radiation is perpendicular to the panel. It was shown that output power efficient up to $22.4 \%, 24.2 \%, 18.64 \%$ for the months May, June and November respectively compared with fixed panel.

\subsection{Output Power Improvement}

In order to get more efficiency of output power from PV solar panel of the tracker system in our study, the modification of the tracker system has been changed by addition another solar panel parallel (back side) and opposite to the first panel (in front side) as shown in Figure 12. The output power have been calculated and plotted against the local time during hours of the day (9:00 AM-14:00 PM) for the month of November.

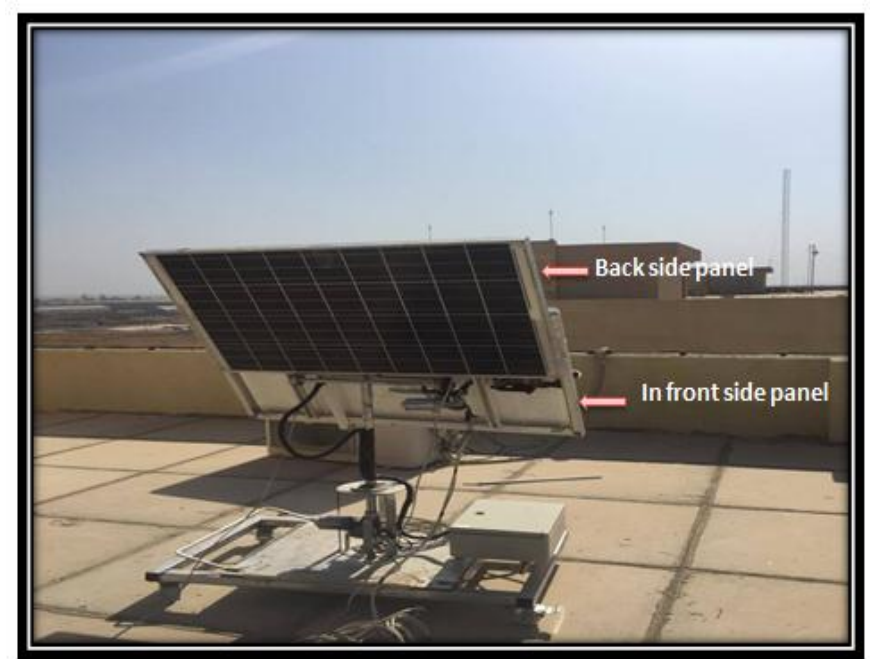

Fig. 12: Addition opposite (rear Side) panel setup arrangement.

Figure 13 shows the variation of the output power-versus-time (Hour) for the fixed panel (FP), single axis panel tracker (SPT), opposite panel tracker (OPT) and sum (SPT + OPT).It shows the output power from (SPT+OPT) give about $56.49 \%$ higher output power than single axis panel tracker (SPT) and $64.60 \%$ compared with the fixed panel (FP). 


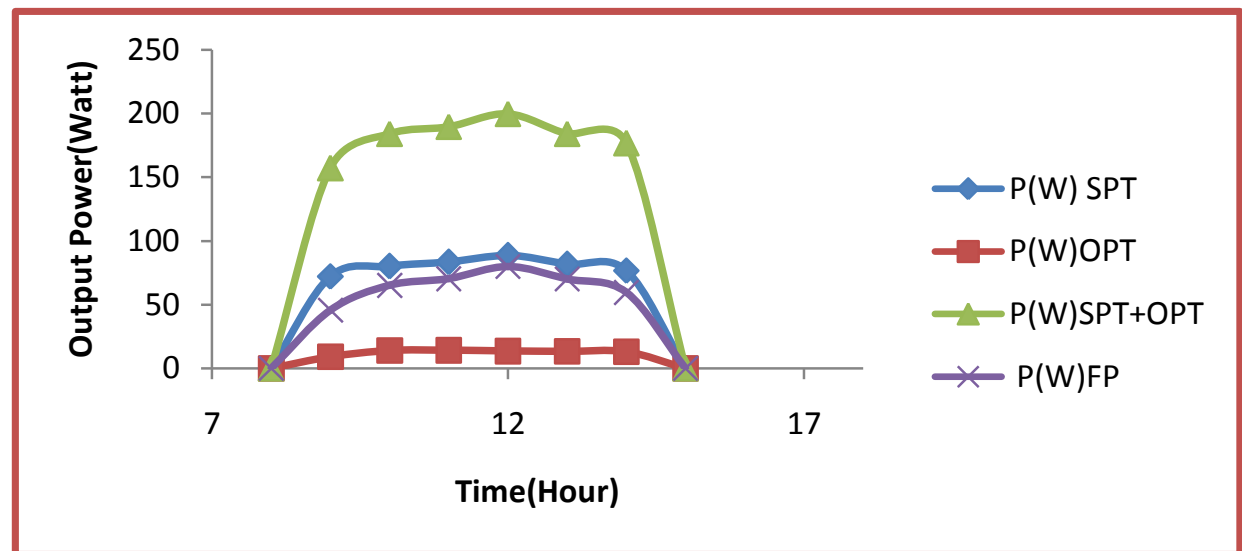

Fig. 13: Output power variation for the Opposite, Fixed, in front and Sum (In front +Rear side) panels with local time.

Finally to improve the efficient power output from the tracker systems in our study the addition of the reflector made of aluminum foil is located at a distance of $173 \mathrm{~cm}$ from the rear side (back side panel), this reflector works as a mirror, it function to reflect the sun radiation towards the opposite panel in order to collect more radiation received from the diffused and albedo radiations. The modified designed tracker was explained in Figure 14.

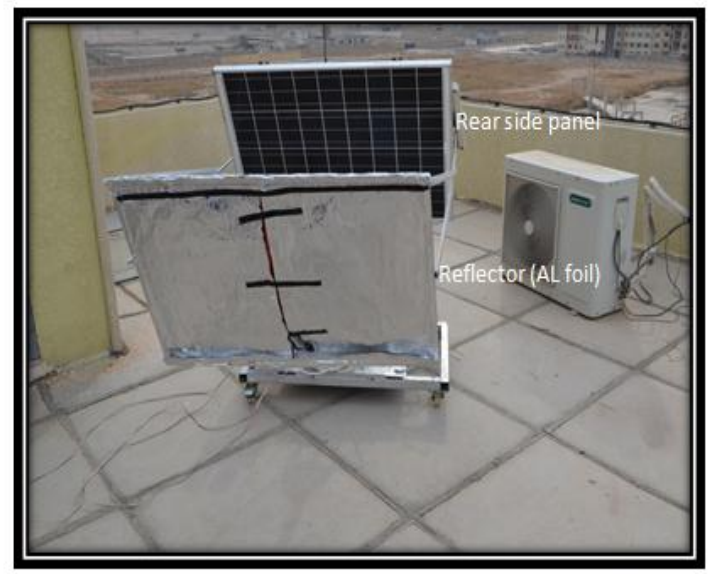

Fig. 14: One axis tracker including (in front, rear side panel and reflector) arrangement.

Figure15 shows the variation of the average output power versus- local time (Hour) for the fixed panel (FP), single panel with opposite panel $(\mathrm{SP}+\mathrm{OP})$ without reflector and single panel with opposite panel and with reflector $(\mathrm{SP}+\mathrm{OP}+\mathrm{R})$. It shows that the output power in single axis with opposite panel and with reflector give about $20.18 \%$ higher output than single axis with opposite panel and the later gives about $64.6 \%$ higher than fixed panel.

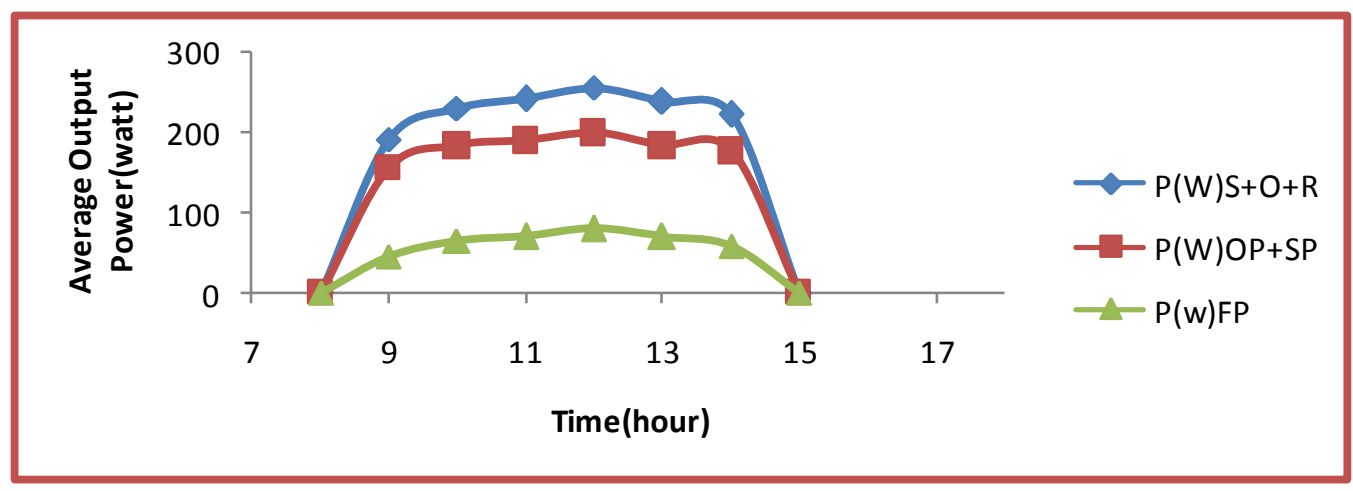

Fig. 15: Comparison the output power variation of fixed, single + opposite panels and (Reflector + Rear side Panel+ single panel) with Time. 
Figure 16 show the histogram curve for the percentage summary of the output power of the designed single axis tracker with fixed and improvement of it by adding the rear side panel with reflectors.

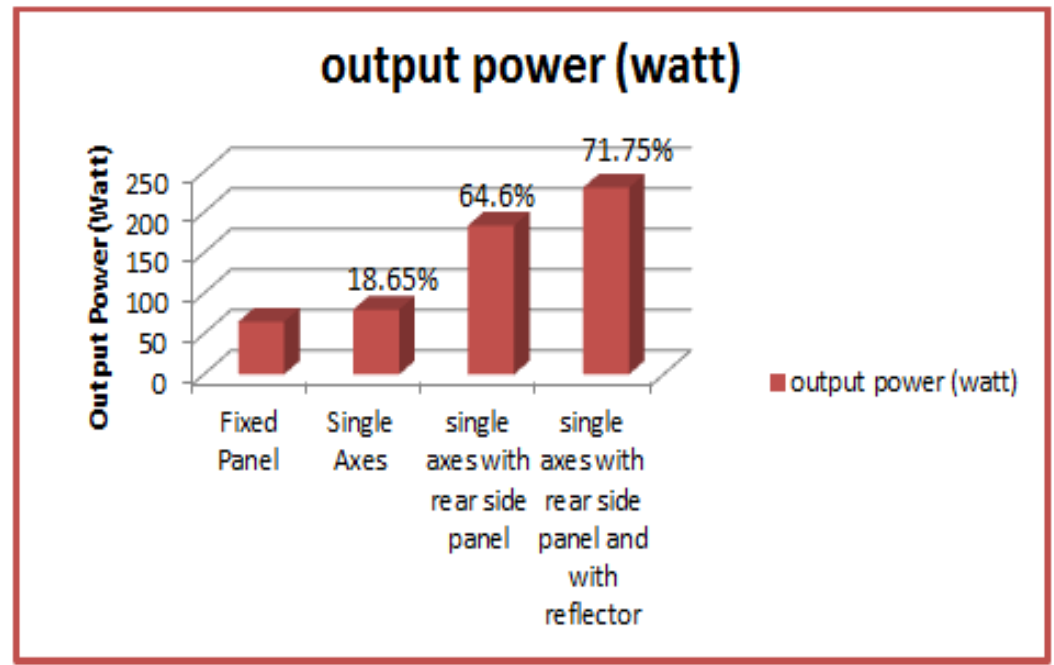

Fig. 16: The Percentage of the Output Power for the Single Axis Tracker, Fixed Panel and addition rear side Panel with Reflector in November 2016.

\section{Conclusions}

Base on the obtained results we can conclude that the proposed technique for design and implement mono axis sun tracker system the following points:

- Tracker system designed and manufactured with a single axis was practically a cheap cost of materials available in local markets.

- The average external power from one axis tracker system designed in our study was improved by $(18-25 \%)$ compared with the fixed panel.

- The output power increased and improved by adding ear side panel and reflector about (65\%) and (70-80\%) respectively.

\section{References}

[1]. J. Patole, Aditi and Shweta Suryawanshi," Design \& Development of Bidirectional Solar Tracking System Implemented in Western Region of Maharashtra", Journal of Engineering, Vol.3, Issue 6, (2013), pp:01-05.

[2]. O. Eseosa and U. Roland, "Design and Simulation of Solar Monitoring Tracking System", Journal of electrical and electronics engineering Vol.4, Issue 5,(2013), pp 35-39.

[3]. S. Deepthi, A.Ponni, R.Ranjitha and R. Dhanabal,"Comparison of Efficiencies of Single Axis Tracking System and Dual Axis Tracking System with Fixed Mount", International Journal of Engineering Science and Innovative Technology, Vol.2, Issue 2, (2013).

[4]. R. Banerjee," Solar Tracking System”, International Journal of Scientific and Research Publications, Volume 5, Issue 3, (2015), ISSN 2250-3153.425-430.

[5]. E.P. I. Edinbarough , "Experimental Study On The Optimum Harvesting Of Sunlight For An Efficient Solar Energy System", University of Texas, Brownsville, 120th A see Annual Conference \&Exposition, American Society for Engineering Education, (2013).

[6]. A. A. H. Ali, "2-Axis solar tracker model", B.SC. Thesis, College of science, Khartoum University, (2013).

[7]. J.Juang and R. Radharamanan," Design of a Solar Tracking System for Renewable Energy", Conference of the American Society for Engineering Education,(2014).

[8]. http://sedonasolartechnology.com/types-of-mounting-systems/

[9]. H. S Akbar, A. I. Siddiq and M .W. Aziz, "'Microcontroller Based Dual Axis Sun Tracking System For Maximum Solar Energy Generation", American Journal of Energy Research, Vol. 5,No.1 (2017), pp:23-27.

[10]. H. S. Akbar, "Design of Sun Tracker System for Solar Energy Applications", Journal of Physics and Research, Vol.1, Issue 1, 2015, PP.29-34.

[11]. F. M. Mohamed, A. S. Jassim, Y. H. Mahmood,” Design and Study of Two Axis Tracking System”, Tikrit Journal of Pure Science, Vol.17, No. 4, (2012), ISSN:1813-1662.

[12]. K.I. Abdul-lateef," A Low Cost Single - Axis Sun Tracker System using Pic Microcontroller”, Diyala Journal of Engineering Sciences, Vol. 05, No.01, (2012), PP.65-78.

[13]. A. Ponniran, A. Hashim and A. Joret, ” A Design of Low Power Single Axis Solar Tracking System Regardless of Motor Speed”, International Journal of Integrated Engineering, Vol.3, No.2 (2011), pp:5-9.

[14]. A. Anuraj and R. Gandhi," Solar Tracking System Using Stepper Motor", international journal of electronic and electrical engineering, Vol. 7, No 6 (2014), pp:561-566.

[15]. V. P. More and V. V. Kulkarni," Design and Implementation of Microcontroller Based Automatic Solar Radiation Tracker", International Journal of Current Engineering and Technology, ISSN 2277 - 4106, Issue-3, (2014). 
[16]. M. H. Jassim, ”Implementation of Solar Energy Tracking System”, Journal of Engineering and Development, Vol. 18, No.4, (2014), pp:124-140.

[17]. A. Abdulrahman, H. A. Al-Nehari, A. N. Almakhlafy, M. Baggash, "Design and Implementation of Solar Tracking System”, International Journal of Engineering and Technical Research, Vol.4, Issue-1, January (2016), pp:71-75.

[18]. O. O. Raoof, "Design and Implementation of Single Axis Sun Trackers Photovoltaic System”, M.Sc. Thesis, College of Science, University of Kirkuk.

[19]. WWW.Kyocera.Com.

[20]. E. J. Okhaifoh and E. D.Okene,'Design and Implementation of A Microcontroller Based Dual Axis Solar Radiation Tracker", Nigerian Journal of Technology (NIJOTECH), Vol.35, No.3, July (2016), pp.584-592. 